\title{
A participação e a influência de Jânio Quadros na política paranaense (1958-1961)
}

\author{
The participation and influence of Jânio Quadros in Paraná politics \\ (1958-1961)
}

\begin{abstract}
Alessandro Batistella ${ }^{1}$
RESUMO

O ano de 2017 marcou o centenário de nascimento de um dos mais controversos políticos brasileiros do século XX: Jânio da Silva Quadros. Natural de Campo Grande (atual estado do Mato Grosso do Sul), Jânio viveu parte da sua infância e adolescência em Curitiba. Na década de 1930, sua família mudou-se para São Paulo, onde Jânio iniciou a sua meteórica carreira política em 1947. Em menos de dez anos, Jânio foi eleito vereador, deputado estadual, prefeito e governador de São Paulo. Em 1960, Jânio foi eleito presidente da República, renunciando após apenas sete meses de mandato. No entanto, convém lembrar que antes de ser eleito presidente, em 1960, Jânio havia sido eleito deputado federal pelo Partido Trabalhista Brasileiro (PTB) do Paraná em 1958. Assim, Jânio teve uma relação pessoal e político-partidária muito próxima com o Paraná. Dessa forma, o presente artigo pretende analisar a participação e a influência política de Jânio Quadros na política paranaense entre os anos de 1958 a 1961.
\end{abstract}

Palavras-chave: Jânio Quadros. Paraná. PTB. Eleições. Campanha da Legalidade.

\section{ABSTRACT}

The year 2017 marks the centenary of the birth of one of the most controversial Brazilian politicians of the 20th century: Jânio da Silva Quadros. Born in Campo Grande (current state of Mato Grosso do Sul), Jânio lived part of his childhood and adolescence in Curitiba. In the 1930s, his family moved to São Paulo, where Jânio began his meteoric political career in 1947. In less than ten years, Jânio was elected councilman, state deputy, mayor and governor of São Paulo. In 1960, Jânio was elected President of the Republic, resigning after only seven months in office. However, it should be remembered that before being elected president in 1960, Jânio had been elected congressman for the Brazilian Labor Party (PTB) of Paraná in 1958. Thus, Jânio had a very close personal-political-partisan relationship with Paraná. Thus, the present article intends to analyze the participation and the political influence of Jânio Quadros in the paranaense politics between the years of 1958 to 1961 .

Keywords: Jânio Quadros. Paraná. PTB. Elections. Legality Campaign.

1 Doutor em História (UFRGS). Professor do Curso de História e do Programa de Pós-Graduação em História da Universidade de Passo Fundo (UPF). E-mail: alessandrobatistella@yahoo.com.br. 


\section{Introdução}

O presente artigo pretende analisar a participação e a influência de Jânio Quadros na politica paranaense entre os anos de 1958 a 1961. Para tais propósitos, primeiramente pretendemos contextualizar o Partido Trabalhista Brasileiro (PTB) do Paraná e analisar os motivos que levaram o PTB paranaense a convidar Jânio a ingressar no partido como candidato a deputado federal pelo Paraná. Em um segundo momento, verificaremos os fatores que contribuíram para que o PTB do Paraná defendesse a chapa Jan-Jan (JânioJango) nas eleições presidenciais de 1960. Posteriormente, analisaremos as eleições de 1960 no Paraná e a influência política de Jânio Quadros no referido pleito. Por fim, analisaremos o impacto da renúncia de Jânio e a Campanha da Legalidade no Paraná.

Jânio da Silva Quadros nasceu em Campo Grande, no então estado do Mato Grosso (e atual estado do Mato Grosso do Sul) em 25 de janeiro de 1917, filho do médico e farmacêutico Gabriel Nogueira Quadros e de Leonor da Silva Quadros. Seus pais eram paranaenses e, desde 1916, proprietários de uma farmácia em Campo Grande².

Em 1925, Jânio e sua família retornaram a Curitiba. Na capital paranaense, Jânio estudou dois anos no Colégio Conselheiro Zacarias (localizado no bairro Alto da Glória); em 1927, seu pai o matriculou no internato do Ginásio Paranaense (atual Colégio Estadual do Paraná), à época dirigido por padres maristas, onde foi colega de Ney Braga (eleito governador do Paraná em 1960). No início de 1931, após o êxito da "Revolução" de 1930, Gabriel Nogueira Quadros - então vinculado ao Partido Republicano Paranaense e membro do governo destituído de Afonso Alves de Camargo ${ }^{3}$, atuando na área da saúde pública - e sua família se mudaram para o estado de São Paulo. Vivendo na capital paulista, Jânio ingressou, em 1935, na Faculdade de Direito de São Paulo, bacharelando-se em 1939 e passando a atuar como advogado e professor secundarista antes de ingressar na carreira política ${ }^{4}$.

Em 1947, o jovem Jânio Quadros, filiado ao pequeno Partido Democrata Cristão (PDC), foi eleito vereador em São Paulo; em 1950, elegeu-se deputado estadual; em 1953, elegeu-se prefeito de São Paulo com 67,4\% dos votos, contando, inclusive, com o apoio de uma ala dissidente do PTB paulista capitaneada pelo general José Porfírio da Paz, que

2 Informações obtidas por meio do verbete eletrônico do Dicionário Histórico-Biográfico Brasileiro (DHBB), do CPDOC/FGV.

3 Afonso Alves de Camargo era a principal liderança do Partido Republicano Paranaense. Presidiu o estado entre 1916-1920 e entre 1928-1930.

4 Informações obtidas por meio do verbete eletrônico do Dicionário Histórico-Biográfico Brasileiro (DHBB), do CPDOC/FGV. 
concorreu como vice de Jânio5; em 1954, Jânio derrotou Adhemar de Barros, do Partido Social Progressista (PSP) e elegeu-se governador de São Paulo com 55\% dos votos, apoiado pela União Democrática Nacional (UDN) e pela ala do PTB liderada pelo general Porfírio da $\mathrm{Paz}^{6}$ (que novamente concorreu como seu vice), Ivete Vargas e Barjas Filho grupo que passou a comandar, a partir de então, o PTB paulista (Cf. BENEVIDES, 1989, p. 51-52, 55-58). Em 1960, Jânio foi eleito presidente da República.

Segundo Maria Victoria Benevides (1989, p. 58), o jovem Jânio Quadros representava uma possibilidade de renovação, indo ao encontro das aspirações populares, o que atraiu a simpatia dos socialistas e até mesmo dos trabalhistas mais identificados com as esquerdas.

[...] O sucesso inicial com as esquerdas não deve ser creditado apenas ao êxito publicitário das campanhas da vassoura e do "tostão contra o milhão". A construção do "mito" começou, provavelmente, durante a atuação de Jânio como deputado estadual em 1951 e 1952. [...] O levantamento de suas intervenções nos Anais da Assembléia Legislativa revela sempre um veemente defensor dos trabalhadores, inclusive para exercerem "o sagrado direito da greve" [...]. Jânio é sempre o mais freqüente crítico da "plutocracia danosa" [...] e da "volúpia dos ricos", denunciando os "salários humilhantes dos trabalhadores". [...]. Jânio ainda defende os migrantes nordestinos, os motoristas de táxi (e seu direito a ponto livre), os líderes sindicais, os professores e os aposentados; denuncia os latifundiários, a corrupção e a violência na polícia e o péssimo atendimento nos serviços de saúde; finalmente, é o nacionalista que repele os monopólios, os trustes e os cartéis (BENEVIDES, 1989, p. 58-59).

Ainda de acordo com Maria Victoria Benevides (1982, p. 14-16), as campanhas de Jânio Quadros são um capítulo à parte na história eleitoral brasileira. Em nenhum outro momento as contradições entre desenvolvimento e atraso, autoritarismo e liberalismo, progressismo e reacionarismo, público e privado, foram tão bem manipulados. Sua atuação seria sempre marcada pela alta incidência de contradições e ambiguidades: nunca se definiu claramente acerca de Getúlio, ora era getulista, ora antigetulista; passava do PTB para a UDN com naturalidade; cortejava a esquerda e os comunistas para depois considerálos como "irrecuperáveis para a democracia"; entre outras coisas. O estilo da campanha para a prefeitura se repete na campanha para o governo do Estado e depois para a presidência da República: os palanques transformavam-se em verdadeiros palcos de

5 Segundo Maria Victoria Benevides (1989, p. 45-52), o PTB paulista inúmeras vezes "abandonou o seu candidato próprio para apoiar o adversário em nome de um 'grande acordo'”. Na eleição à prefeitura de São Paulo, em 1953, também não foi diferente: o candidato oficial do partido era Francisco Antonio Cardoso, apoiado pelo governador Lucas Nogueira Garcez (do PSP) e por uma coligação considerada imbatível, reunindo oito partidos. Entretanto, a campanha "Nós queremos Cardoso" não conseguiu unir os petebistas e os grupos de Toledo Piza, Castro Neves, Scalamandré Sobrinho e Ataliba Leonel apoiaram a aliança com o PDC e o nome de Porfírio da Paz como vice de Jânio.

6 Em 1954, o PTB lançou Wladimir de Toledo Piza como candidato ao governo paulista, mas o seu nome não conseguiu unir o partido (Cf. BENEVIDES, 1989). 
tragicomédias: Jânio tomava injeções em público, simulava desmaios, comia sanduíches de mortadela levados nos bolsos e era carregado nos ombros do povo.

Entretanto, antes de ser eleito presidente da República em 1960, Jânio Quadros foi eleito deputado federal em 1958 pelo PTB do Paraná, sendo inclusive o deputado mais votado no estado. Contudo, a eleição de Jânio como deputado federal pelo PTB paranaense é um tema que não foi praticamente analisado por historiadores, cientistas políticos e jornalistas que se dedicaram a estudar a biografia ou a trajetória politica de Jânio Quadros ${ }^{7}$.

Portanto, além de ter passado alguns anos da sua infância e adolescência em Curitiba, Jânio Quadros também teve uma intensa relação politica com o Paraná, sobretudo entre os anos de 1958 a 1961. Nesse curto recorte temporal, Jânio teve um importante papel para a vitória eleitoral do PTB nas eleições estaduais de 1958, foi cortejado sistematicamente pelos principais candidatos ao governo do Paraná em 1960, além de também ter obtido uma excelente votação no estado na eleição presidencial de $1960^{8}$.

\section{O Ingresso de Jânio Quadros no PTB Paranaense e as Eleições de} 1958

O PTB do Paraná nasceu do sindicalismo oficial e do esforço do interventor Manoel Ribas e de políticos ligados à interventoria do estado, que objetivavam criar uma agremiação que canalizasse o sindicalismo estadonovista em uma frente de defesa do legado trabalhista de Getúlio Vargas. Criado oficialmente em julho de 1945, o PTB paranaense foi inicialmente comandado por líderes sindicais - dentre eles Maximino Zanon, o primeiro presidente do partido - e encontrava-se estruturalmente fragilizado, o que contribuiu para o fraco desempenho eleitoral do partido nas eleições de $1945^{9}$.

No entanto, ainda nos seus primeiros anos de existência, o PTB do Paraná vivenciou um processo de "elitização" interna, com o ingresso de inúmeros políticos profissionais, empresários e profissionais liberais - sobretudo advogados e funcionários públicos -, que gradativamente foram ocupando os principais postos de mando dentro do partido. Nesse sentido, convém ressaltar que a maioria desses novos integrantes do PTB eram pessoas que possuíam algum tipo de vínculo com o abastado empresário Moysés Lupion, o que contribuiu para um processo de "lupionização" do partido. Dentre estes novos integrantes

7 Ver, por exemplo, os trabalhos de Maria Victoria Benevides (1982), Vera Chaia (1991), Nelson Valente (1993) e Jefferson Queler (2008).

8 Mais detalhes ver Batistella (2016).

9 Nas eleições à Câmara dos Deputados, o PSD elegeu seis deputados, a UDN elegeu dois e o PTB apenas um. Para o Senado foram eleitos dois pessedistas. 
convém destacar Abilon de Souza Naves ${ }^{10}$, que ascendeu ao posto de vice-presidente da Executiva estadual em 1946, assumindo a presidência provisória do partido em janeiro de 1948, após a morte de Maximino Zanon, e sendo eleito presidente efetivo em outubro de 1949.

Amigo íntimo de Manoel Ribas e considerado o seu herdeiro político, Lupion era dono de um verdadeiro império econômico e ambicionava chegar ao governo do Paraná nas eleições de 1947. Para tanto, utilizou todo o seu poderio financeiro para comprar jornais, rádios e exercer grande influência política não somente junto ao seu partido, o Partido Social Democrático (PSD), mas também dentro do PTB do Paraná, cuja Executiva estadual passou a defender incondicionalmente a sua candidatura.

Apesar das disputas internas dentro do PSD e da oposição de uma ala dentro do PTB, Moysés Lupion conseguiu articular uma grande coalizão interpartidária, sendo oficializado candidato pela coligação PSD, PTB, UDN e Partido de Representação Popular (PRP). Nas eleições de janeiro de 1947, Lupion derrotou Bento Munhoz da Rocha Neto ${ }^{11}$, do Partido Republicano (PR). Por sua vez, o PTB paranaense teve um desempenho mediano nas eleições legislativas estaduais, ficando atrás do PSD e da UDN ${ }^{12}$.

O primeiro governo de Moysés Lupion (1947-1951) foi caracterizado por uma série de crises e desentendimentos políticos com a sua base aliada, culminando com o rompimento com a UDN (oficializado no início de $1948^{13}$ ) e com o PTB (oficializado em setembro de 1948). Dessa forma, a união das forças antilupionistas (que aglutinou diversos partidos, como PR, UDN e PRP, além de uma significativa fração do PTB - que oficialmente manteve-se neutro - e de uma ala dissidente do PSD) foi determinante para a vitória esmagadora de Bento Munhoz da Rocha Neto nas eleições para o governo do Paraná em 1950, derrotando o candidato lupionista Angelo Lopes (PSD).

Nas eleições legislativas de 1950, o PTB paranaense, embora tenha optado em abster-se das eleições para a senadoria ${ }^{14}$ (não concorrendo com candidato próprio e não

10 Abilon de Souza Naves nasceu em 1905, em Uberaba (MG) e chegou ao Paraná em meados da década de 1940. Contador de formação, atuou como delegado regional do Instituto de Aposentadoria e Pensões dos Comerciários (IAPC) e trabalhou na área comercial do jornal Gazeta do Povo (NEVES, 2002, p. 138).

11 Filho de Caetano Munhoz da Rocha (que presidiu o Paraná entre os anos de 1920-1928 e um dos líderes do Partido Republicano Paranaense) e genro de Afonso Alves de Camargo (o governador destituído pela Revolução de 1930), Bento Munhoz da Rocha Neto era considerado o herdeiro político das antigas oligarquias da Primeira República.

12 De um total de 37 cadeiras na Assembleia Legislativa, o PSD elegeu 16 deputados, enquanto a UDN elegeu sete, o PTB elegeu seis, o PR elegeu quatro, o PRP elegeu dois, o PSP um e o PCB também um.

13 A partir de então a UDN empreendeu uma ferrenha oposição ao governo Lupion, tornando-se sua implacável e eterna inimiga.

14 Nas eleições ao Senado, o PSD paranaense sofreu mais uma derrota: Raul Vaz, amigo íntimo de Lupion, perdeu a eleição para o udenista Othon Mader, um dos principais adversários políticos do governador paranaense. 
apoiando oficialmente nenhum candidato) e enfrentasse problemas estruturais e financeiros, apresentou um significativo crescimento eleitoral em virtude da força simbólica do getulismo e da doutrina trabalhista ${ }^{15}$, elegendo três deputados federais ${ }^{16}$ e doze deputados estaduais ${ }^{17}$ (que representavam diversas cidades do interior do estado, evidenciando que, sob o comando de Abilon de Souza Naves, o PTB estava gradativamente se estruturando e crescendo no interior do Paraná).

Durante o governo de Bento Munhoz da Rocha Neto (1951-1955), o PTB paranaense encontrava-se dividido em dois grupos: de um lado, os independentes; de outro, os bentistas. Assim, o partido optou por se manter em uma posição de neutralidade pragmática, isto é, não apoiou oficialmente o governador paranaense, embora alguns petebistas tenham apoiado e ocupado postos do governo. Contudo, a posição periférica que - PTB ocupava no governo estadual contribuiu para aumentar o descontentamento dos trabalhistas, que decidiram romper oficialmente com o governador em abril de 1954.

Nas eleições legislativas de 1954, o PTB paranaense teve um desempenho eleitoral estável, elegendo quatro deputados federais ${ }^{18}$ e onze deputados estaduais ${ }^{19}$. Nesse mesmo ano o PTB também concorreu, pela primeira vez, à senatoria e lançou um candidato próprio na primeira eleição direta à prefeitura de Curitiba. Porém, o partido, em ambos os pleitos, não obteve êxito. ${ }^{20}$

Em 1955, o PTB paranaense concorreu, pela primeira vez, com candidato próprio ao governo do Paraná. Com a desistência de Abilon de Souza Naves, o partido lançou a candidatura do médico e deputado estadual Mário Batista de Barros. Embora contasse com o apoio oficial do PR, a candidatura de Mário de Barros não foi unanimidade no PTB, uma vez que diversos petebistas declaravam publicamente oposição à sua candidatura e o apoio à candidatura do senador e ex-governador Moysés Lupion (PSD). Portanto, o PTB

15 Mais detalhes ver Batistella (2016).

16 No que tange à Câmara dos Deputados, houve um grande equilíbrio: o PSD elegeu três deputados; o PTB também três e a coligação UDN/PR/PST/PRP/PL igualmente três.

$17 \mathrm{Na}$ Assembleia Legislativa, por sua vez, embora o PSD tenha conquistado 16 cadeiras, o grande vencedor foi o PTB, que elegeu 12 deputados (o dobro da eleição anterior). Contudo, convém lembrar que o crescimento eleitoral do PTB não significou um jogo de soma zero, isto é, não houve uma simples transferência das cadeiras udenistas e pessedistas para os petebistas, uma vez que houve um aumento do número de cadeiras - de 37, em 1947, para 45, em 1950. Quanto aos demais partidos, a UDN conquistou oito cadeiras, o PR seis, o PSP duas e o PRP uma cadeira.

18 No que tange à Câmara dos Deputados, houve um equilíbrio entre os três principais partidos: o PSD elegeu quatro deputados, PTB também quatro, a UDN três, o PR dois e o PSP um.

19 Por sua vez, no legislativo estadual houve um grande equilíbrio entre o PTB e o PSD, com cada um dos partidos elegendo 11 deputados estaduais, enquanto a UDN elegeu oito, o PR e o PSP elegeram sete cada um e o emergente PDC elegeu um deputado - totalizando 45 deputados estaduais.

$20 \mathrm{Na}$ disputa ao Senado, o petebista Parahylio Borba foi derrotado pelo ex-governador Moysés Lupion e por Alô Guimarães, ambos do PSD. Por sua vez, o major Ney Braga (PR-PSP) foi eleito prefeito de Curitiba, derrotando Estevam Ribeiro de Souza Neto (PTB), Wallace Tadeu de Mello e Silva (PST), Alfredo Pinheiro Júnior (PSD), Amâncio Moro (PL), João Cid Portugal (PDC), Roberto Barrozo e Manoel Aranha (UDN). 
encontrava-se desunido justamente na primeira eleição em que concorreu com candidato próprio ao governo do Estado e, por isso, houve pouco empenho de alguns grupos dentro do partido em apoiar a campanha de Mário de Barros. Assim, Lupion venceu a eleição derrotando Mário de Barros (PTB-PR), o senador Othon Mader (UDN), o deputado federal Luís Carlos Tourinho (PSP) e Carlos Amoreti Osório (PSB) -, retornando ao governo do Paraná.

Não obstante as derrotas eleitorais nas eleições para a senatoria, para a prefeitura de Curitiba e para o governo do Paraná, a partir da segunda metade da década de 1950 o PTB paranaense encontrava-se fortalecido estruturalmente em todo o estado e apresentava um crescimento eleitoral significativo, consolidando-se como uma importante força politica no Paraná, o que catalisou uma rivalidade com o PSD paranaense. Desse modo, enquanto em nível nacional PTB e PSD formaram uma sólida aliança, responsável pela eleição de Juscelino Kubitschek e João Goulart para a presidência e vice-presidência da República respectivamente, no Paraná pessedistas e petebistas tomaram rumos opostos.

Assim, durante o segundo governo de Moysés Lupion (1956-1961), Abilon de Souza Naves, embora fosse constantemente cortejado pelo governador paranaense e fortemente pressionado pela ala lupionista do partido a apoiar oficialmente o governo, optou em colocar o PTB em oposição ao governo Lupion, contando, inclusive, com o apoio de importantes lideranças dentro do partido, sobretudo das alas nacionalista e reformista (Cf. BATISTELLA, 2016).

Diferentemente da época do primeiro governo Lupion, agora o PTB encontrava-se estruturado e consolidado como um partido popular e forte eleitoralmente. Em virtude disso, Souza Naves e outras lideranças trabalhistas argumentavam que o PTB deveria ter uma maior participação no governo estadual e que deveria ser realmente valorizado demonstrando, assim, que não havia esquecido o tratamento dado ao partido por Lupion durante o seu primeiro governo.

Apesar das pressões da ala lupionista do PTB e de ser constantemente atacado pela imprensa pessedista/lupionista, Souza Naves mostrava-se irredutível na sua decisão e tinha força política para mantê-la, uma vez que havia se consolidado como a principal liderança dentro do partido, comandando-o com "mão-de-ferro". Com estreitos vínculos com João Goulart, era vice-presidente nacional do $\mathrm{PTB}^{21}$ e ambicionava lançar-se como candidato ao Senado em 1958 e ao governo do Paraná em 1960.

$21 \mathrm{Na}$ VI Convenção Nacional do PTB, realizada em maio de 1952 - a mesma que elegeu João Goulart presidente nacional do partido -, Abilon de Souza Naves ascendeu à Executiva Nacional do PTB como quarto vice-presidente. A partir de então, Souza Naves aproximou-se de Jango, de quem se tornou um fiel aliado, tornando-se, a partir da Convenção Nacional de julho de 1953, o segundo vice-presidente nacional do PTB. 
Para tais propósitos, durante o ano de 1957 Souza Naves adotou uma série de estratégias cujo objetivo era fortalecer o PTB e a sua candidatura ao Senado: esvaziou a ala lupionista e descartou qualquer possibilidade de entendimento com o governador Lupion; atraiu para o partido alguns empresários e cafeicultores que disponibilizariam um importante aporte financeiro para a campanha eleitoral; convidou os deputados estaduais dissidentes do Partido Republicano (PR) ${ }^{22}$ a ingressarem no PTB; e, por fim, deu uma grande cartada política: aproximou-se de Jânio Quadros e propôs que o governador de São Paulo concorresse a deputado federal pelo PTB do Paraná.

Sem dúvida, o convite de Souza Naves a Jânio Quadros tinha um claro objetivo eleitoral: encorpar o PTB paranaense com um político popular e conhecido nacionalmente que pudesse atrair mais eleitores para o partido - sobretudo na região norte do estado, onde muitos habitantes eram de origem paulista. Como Jânio estava impedido de disputar algum cargo eletivo em São Paulo, a proposta de concorrer como deputado federal pelo Paraná lhe agradou, pois assim ele teria a possibilidade de ocupar uma cadeira na Câmara dos Deputados até as eleições presidenciais de 1960, a sua grande ambição.

Contudo, a relação de Jânio Quadros com o PTB sempre foi bastante complexa e contraditória: apoiado por algumas alas do PTB paulista, Jânio dividia opiniões no Diretório Nacional do partido, que temia o crescimento do janismo dentro das hostes petebistas. Assim, o seu ingresso no PTB do Paraná foi visto com reservas pelo Diretório Nacional e tendia mais a favorecer eleitoralmente os petebistas paranaenses e o próprio Souza Naves.

A confirmação da candidatura de Jânio Quadros pelo PTB paranaense ocorreu na Convenção estadual de 14 de dezembro de 1957, na qual foram lançados 17 candidatos à Câmara dos Deputados e 50 candidatos à Assembleia Legislativa, além de também oficializar-se a candidatura de Souza Naves para o Senado e de Nelson Maculan como seu suplente (GAZETA DO POVO, 17/12/1957, p. 3).

Entretanto, em 1958, Jânio Quadros entrou em rota de colisão com o PTB de São Paulo: a sucessão estadual paulista estava polarizada entre Carlos Alberto de Carvalho Pinto (PDC), candidato apoiado por Jânio, e Adhemar de Barros (PSP) ${ }^{23}$. Entretanto, como lembra Maria Victoria Benevides (1989, p. 65), a direção nacional do PTB (especialmente João Goulart) tinha interesse em uma coalizão com o PSP em função de outros acordos estaduais. Desse modo, Goulart autorizou Ivete Vargas - na presidência do PTB paulista desde 1958 - a selar o apoio a Adhemar.

22 Os deputados estaduais dissidentes do PR eram Amaury de Oliveira e Silva, Silvino Lopes de Oliveira e Chafic Cury.

$23 \mathrm{Na}$ sucessão paulista, apoiado por petebistas rebeldes, o candidato janista Carvalho Pinto obteve $49 \%$ dos votos e venceu Adhemar de Barros, que obteve 40\% (BENEVIDES, 1989, p. 66). 
Jânio Quadros, por sua vez, revoltado com o apoio do PTB paulista a Adhemar, disparou a sua metralhadora giratória, declarando que o "PTB não era um partido, mas uma quadrilha, um bando de negociatas, de legenda prostituída" (GAZETA DO POVO, 30/07/1958, p. 1), o que gerou um grande mal-estar e uma forte reação do grupo de Ivete Vargas e do Diretório Nacional, que passaram a combater Jânio dentro das hostes petebistas - uma vez que ele era candidato a deputado federal pelo PTB do Paraná.

Para tentar contornar a situação perante o eleitorado getulista/trabalhista e ao próprio PTB, Jânio Quadros negou as ofensas em uma carta a Souza Naves (DIÁRIO DA TARDE, 14/08/1958, p. 1). A carta de Jânio Quadros a Souza Naves, publicada em alguns jornais Diário da Tarde e Estado do Paraná -, foi duramente criticada pelos jornais pessedistas, que a chamaram de "carta marcada" (O DIA, 15/08/1958, p. 4), isto é, uma manobra de Souza Naves e Jânio para apaziguar os ânimos nas hostes petebistas. Sem dúvida, o PSD estava ciente que Jânio Quadros poderia ser um fator de desequilíbrio em favor do PTB nas eleições de outubro de 1958 e frequentemente atacava a sua candidatura, acusando-o de ser um reacionário, antinacionalista e que não possuía nenhum vínculo com o Paraná:

[...] Já uma vez afirmamos, e voltamos a repeti-lo hoje: a nos pouco interessa que Jânio seja candidato pelo PTB, pela UDN, pelo PR ou seja por que legenda for. O que nos interessa, o que nos causa repulsa, é que seja candidato a deputado federal pelo Paraná. Não por ter nascido fora de nosso Estado, já que muitas de nossas expressões políticas regionais atuais ou do passado são ou eram oriundas de outros Estados. Mas porque Jânio funcionalmente não poderá ser um advogado parlamentar dos interesses paranaenses, umbilicalmente ligado como esta aos interesses econômicos de São Paulo, basicamente contundentes com o nosso domínio cafeeiro. E porque sob o ponto de vista da democracia brasileira Jânio constituiu, com seu aventurismo reacionário, um perigo, um perigo antinacional que os paranaenses estariam insuflando se lhe dessem uma cadeira roubada ao Paraná nas urnas de outubro vindouro (O DIA, 23/08/1958, p. 4).

Apesar dos ataques dos pessedistas e dos desentendimentos com o Diretório Nacional petebista, a inclusão de Jânio Quadros no PTB paranaense foi uma grande cartada eleitoral de Souza Naves, que agora possuía um nome de peso para atrair votos para a legenda petebista. Soma-se a isso o fato de Souza Naves ter estreitado vínculos com o setor cafeeiro do norte do estado e com alguns setores empresariais paranaenses objetivando angariar apoio político e financiamento para a campanha petebista (Cf. BATISTELLA, 2016).

No entanto, a presença de candidatos milionários, que gastavam fortunas em suas campanhas eleitorais, provocou grandes descontentamentos em alguns grupos dentro do PTB paranaense que, poucos meses antes do pleito de outubro de 1958, utilizando-se de um conhecido clichê janista, denunciavam a disputa do "milhão contra o tostão" nas hostes 
trabalhistas. Dessa forma, ocorreu uma polarização e fomentou-se uma rivalidade entre os candidatos petebistas: de um lado, estava a "ala dos ricos"; de outro, a "ala dos pobres", que acusavam os "plutocratas" de utilizar o seu poderio econômico para comprar diretórios e contratar cabos eleitorais em suas regiões de origem, exercendo, assim, uma concorrência desleal. As disputas pelas bases eleitorais regionais entre os petebistas da "ala rica" e da "ala pobre" contribuíram para acirrar os ânimos dentro do partido, além de também servir de munição para os jornais pessedistas atacarem a candidatura de Souza Naves ao Senado.

À medida que as eleições de outubro se aproximavam, os jornais pessedistas também passaram a denunciar, com visíveis intenções eleitorais, a aproximação, no âmbito nacional, entre o PTB e o PCB, ao mesmo tempo em que destacavam notícias em que a lgreja católica "condenava tais atividades subversivas". Nesse sentido, convém lembrar que o imaginário anticomunista foi uma estratégia eleitoral amplamente utilizada nos anos 1950 e 1960. No entanto, a aliança entre comunistas e trabalhistas era constantemente negada por Souza Naves e os demais candidatos petebistas nos comícios e na imprensa.

Não obstante as disputas internas e os contundentes ataques da imprensa pessedista, o PTB do Paraná obteve um considerável desempenho nas eleições de outubro de 1958, elegendo Souza Naves senador ${ }^{24}$, conquistando a prefeitura de Curitiba com o general Iberê de Mattos $^{25}$ e aumentando o número de deputados em nível federal e estadual, elegendo seis deputados federais ${ }^{26}$ e 13 deputados estaduais ${ }^{27}$. Por sua vez, Jânio Quadros foi eleito o deputado federal mais votado no Paraná, obtendo 78.810 votos $^{28}$ (IPARDES, 1989, p. 113).

Portanto, as eleições de 1958, do ponto de vista eleitoral, foram um grande divisor de águas para o Partido Trabalhista Brasileiro do Paraná. Adotando uma postura oposicionista

24 Abilon de Souza Naves tornou-se o primeiro senador trabalhista do Paraná - derrotando o candidato lupionista José Munhoz de Melo (PSD) e o udenista Cel. Francisco Paula Soares Neto, que concorreu pela Frente Democrática (coligação entre UDN, PR e PSP) -, elegendo-se com uma grande margem de votos: Souza Naves obteve 291.200 votos, enquanto José Munhoz de Melo obteve 184.379 votos e o Cel. Francisco Paula Soares Neto obteve 62.641 votos (IPARDES, 1989, p. 108).

$25 \mathrm{Na}$ disputa pela prefeitura de Curitiba - um dos postos políticos mais cobiçados entre os partidos - o PTB também conquistou mais uma grande vitória, elegendo o Gen. Iberê de Mattos prefeito da capital. Além de derrotar o seu cunhado Luís Carlos Tourinho (PSP), o Gen. Iberê também derrotou Felipe Simão, que contava com o apoio do atual prefeito Ney Braga, que, embora gozasse de grande prestígio e estava em ascensão política, não conseguiu eleger o seu sucessor. Mais detalhes ver Rehbein (2008).

26 Na Câmara dos Deputados, o PTB obteve um excelente desempenho, elegendo seis deputados, enquanto o PSD elegeu quatro, a Frente Democrática (UDN-PR-PSP) elegeu dois, o PRP elegeu um e o emergente PDC também um deputado.

27 No que tange às eleições à Assembleia Legislativa, embora o PTB também tenha apresentado um crescimento, passando de 11 para 13 deputados, o grande vencedor foi o PSD, que aumentou a sua bancada em seis deputados, passando de 11 para 17. Observa-se ainda que a Frente Democrática (formada por UDN e PR) elegeu sete deputados; o PSP quatro; o PDC três; e a Frente Trabalhista Cristã (coligação entre PRP, PTN e PRT) elegeu um deputado.

28 Contudo, convém lembrar que Jânio jamais chegou a colocar os pés no Congresso. Após ser empossado em fevereiro de 1959, solicitou uma série de licenças para tratar de interesses particulares, renunciando ao seu mandato de deputado federal em janeiro de 1961, para assumir a presidência da República. 
ao governo Lupion e à prefeitura de Ney Braga, o partido apresentou, de uma maneira geral, um significativo crescimento eleitoral e consolidou-se como uma grande força política no Paraná.

O crescimento eleitoral do PTB paranaense deve-se, sobretudo, a dois fatores. Em primeiro lugar, ao pragmatismo de Souza Naves, que, além de utilizar o legado simbólico getulista-trabalhista, atraiu grande quantidade de recursos financeiros para a campanha eleitoral do partido à medida que se aproximou dos cafeicultores e de setores empresariais. Em segundo lugar, também se deve levar em consideração a inclusão de Jânio Quadros na chapa petebista, que, apesar de não ser unanimidade dentro do partido, angariou muitos votos para a legenda e contribuiu para a eleição de alguns deputados.

O desempenho eleitoral do PTB paranaense em 1958, em particular a eleição, por uma grande margem de votos, de Souza Naves ao Senado gerou uma grande euforia entre os petebistas, que diziam que Souza Naves já era o governador virtualmente eleito em 1960.

\section{O PTB do Paraná e a Chapa Jan-Jan em 1960}

Após as eleições de 1958, o PTB paranaense manteve a sua posição oposicionista ao governador Lupion e se articulava para a sucessão estadual de 1960, cujo candidato seria o agora senador Abilon de Souza Naves. Embora os petebistas esbanjassem otimismo e acreditassem que a vitória de Souza Naves era somente uma questão de tempo, em 1959 também começou a ganhar força a candidatura de Ney Braga (PDC), ex-prefeito de Curitiba e o segundo deputado federal mais votado no Paraná em 1958.

Assim, no primeiro semestre de 1959, Souza Naves e Ney Braga já se encontravam em campanha eleitoral e, inclusive, iniciaram uma disputa nos bastidores visando a conquistar o apoio de Jânio Quadros no pleito de 1960 (GAZETA DO POVO, 31/03/1959, p. 3). Sem dúvida, quem conquistasse o apoio do ex-governador paulista (e agora deputado federal pelo PTB do Paraná) teria um grande trunfo, que certamente garantiria muitos votos.

Por sua vez, Jânio Quadros, que articulava a sua candidatura à presidência da República pelo PDC, encontrava-se em uma encruzilhada, uma vez que possuía vínculos de amizade e político-partidários tanto com o PDC de Ney Braga quanto com o PTB de Souza Naves. Assim, Jânio optou pela neutralidade, embora barganhasse o apoio do PDC e do PTB à sua candidatura presidencial.

Posteriormente, Souza Naves e outros líderes do PTB paranaense passaram a defender a candidatura de Jânio Quadros pelo PTB, passando a articular uma aliança 
denominada Jan-Jan (Jânio e Jango) (GAZETA DO POVO, 04/06/1959, p. 4). Embora Souza Naves tentasse convencer João Goulart, a chapa Jan-Jan era combatida por algumas alas - como o grupo de Leonel Brizola e, sobretudo, as correntes nacionalistas (D’ARAÚJO, 1996, p. 125). Assim, a candidatura de Jânio pelo PTB acabou sendo gradativamente descartada dentro do partido, ao mesmo tempo em que cresciam as possibilidades de uma nova aliança com o PSD em torno da chapa Lott-Jango.

Em entrevistas aos jornais, Souza Naves mostrava-se descontente com a provável aliança com o PSD, declarando que "se isso ocorresse se manteria neutro, pois não poderia aliar-se com o PSD paranaense, a quem fazia oposição" (GAZETA DO POVO, 19/05/1959, p. 3). Na verdade, Souza Naves encontrava-se em uma situação difícil: além de ser próximo de Jânio Quadros, também ambicionava contar com o seu valioso apoio para as eleições estaduais de 1960, repetindo, assim, a fórmula de sucesso utilizada no pleito de 1958. Porém, também tinha ciência de que a confirmação do acordo com o PSD e o lançamento da chapa Lott-Jango para a sucessão presidencial afastaria qualquer possibilidade de contar com o apoio oficial de Jânio Quadros, que provavelmente tenderia a apoiar a candidatura do seu correligionário pedecista Ney Braga.

Desse modo, conclui-se que os esforços de Souza Naves e dos petebistas do Paraná em defender o lançamento da chapa Jan-Jan deve-se exclusivamente a uma estratégia política regional, uma vez que a eleição de 1958 havia comprovado de que o apoio de Jânio Quadros tinha um peso eleitoral significativo no Paraná. Porém, a insistência de Souza Naves em defender a candidatura Jan-Jan lhe rendeu alguns problemas dentro do PTB nacional, uma vez que passou a sofrer a oposição de algumas alas. Inclusive, a imprensa especulou que João Goulart iria excluí-lo da nova Executiva Nacional, que seria escolhida em outubro de 1959.

No entanto, na referida convenção, Souza Naves foi mantido como um dos vicepresidentes do partido. Reeleito pela terceira vez seguida como vice-presidente do PTB nacional, Souza Naves gozava da confiança de João Goulart, de quem era um fiel aliado. Porém, parece que a opção de Souza Naves em apoiar a candidatura de Jânio estremeceu um pouco as relações entre ambos - inclusive os jornais cariocas mencionavam uma carta escrita por Souza Naves rompendo com Jango (GAZETA DO POVO, 15/12/1959, p. 1, 6).

De qualquer maneira, no final de 1959, Souza Naves passou a adotar uma posição dúbia com relação a Jânio Quadros, negando que houvesse compromissos entre o PTB paranaense e Jânio (GAZETA DO POVO, 18/11/1959, p. 1), porém não descartando um futuro compromisso, uma vez que ainda possuía esperanças que a chapa Jan-Jan fosse homologada na XII Convenção Nacional do PTB, que seria realizada em fevereiro de 1960. 
Entretanto, Souza Naves não viveu para defender a sua posição na Convenção. Em 12 de dezembro de 1959, durante um jantar realizado em sua homenagem (organizado pelos seus ex-colegas do Instituto de Aposentadorias e Pensões dos Comerciários (IAPC), realizado na Sociedade Morgenau, em Curitiba), sofreu um infarto fulminante e faleceu aos 54 anos de idade. ${ }^{29}$

Conforme o depoimento do trabalhista Léo de Almeida $\operatorname{Neves}^{30}$ (2002, p. 145):

\begin{abstract}
O funeral na manhã de domingo [13/12/1959] teve inigualável comparecimento popular. Vieram personalidades nacionais e paranaenses para homenageá-lo. Houve uma cena inusitada e interessantíssima. O Jânio chegou esbaforido, e o João Goulart já estava ao lado do caixão. Então o Jânio Quadros se aproximou pelo outro lado, fez rápida prece e depois agarrou, por baixo do caixão, a mão de João Goulart e ficaram de mãos dados por alguns minutos. Ele estava tentando cativar João Goulart para sua candidatura a presidente da República no ano seguinte e tinha esperança de ser candidato pelo próprio PTB.
\end{abstract}

Durante o funeral, João Goulart, além de lamentar a morte de seu amigo, mostrava-se preocupado com os rumos do PTB paranaense (DIÁRIO DA TARDE, 14/12/1959, p. 1), que, por sua vez, estava atordoado com a repentina perda do seu líder. De fato, uma grande incógnita emergia nos círculos políticos paranaenses no final do ano de 1959: como se comportaria o PTB do Paraná sem Souza Naves? Quem comandaria o partido? Quem seria o candidato petebista para a sucessão estadual de 1960 ?

\title{
O “Fator Jânio Quadros” e as Eleições de 1960 no Paraná
}

Após a morte de Abilon de Souza Naves uma pergunta tomou conta do noticiário político paranaense: quem seria agora o candidato petebista ao governo do estado? Sem o seu principal líder e aglutinador, o PTB do Paraná estava dividido em diversos nomes e longe de um consenso. Contudo, o nome que foi paulatinamente ganhando força dentro do partido era o do agora senador Nelson Maculan, que contava, inclusive, com o apoio de João Goulart.

Às vésperas da Convenção estadual, programada para fevereiro de 1960, a disputa pelo posto de candidato petebista polarizou-se entre Nelson Maculan e o deputado estadual Amaury de Oliveira e Silva, que, por orientação de João Goulart, acabou renunciando a sua candidatura. Dessa forma, na Convenção estadual do PTB paranaense, realizada nos dias 3

29 Após a morte de Souza Naves, o suplente Nelson Maculan assumiu a sua cadeira no Senado, enquanto o PTB paranaense passou a ser comandado interinamente pelo deputado estadual Antônio Annibelli, primeiro vice-presidente.

30 Léo de Almeida Neves (1932-...) foi uma das principais lideranças da ala reformista do PTB paranaense. Foi eleito primeiro suplente de deputado estadual em 1958. Após a morte de Souza Naves, foi convidado por Jango a integrar a Executiva nacional do partido. Em 1966, foi eleito deputado federal pelo Movimento Democrático Brasileiro (MDB), porém foi cassado em março de 1969 pelo Al-5. 
e 4 de fevereiro de 1960 - que contou com a presença de João Goulart -, Nelson Maculan foi oficializado, por unanimidade, como o candidato petebista à sucessão estadual.

Em âmbito nacional, nos dias 17, 18 e 19 de fevereiro de 1960 ocorreu a XII Convenção Nacional do PTB - que não contou com a presença de Fernando Ferrari, já em campanha eleitoral como vice de Jânio Quadros -, na qual foi homologada a coalizão com o PSD e o lançamento da chapa Lott-Jango para a presidência da República. Apesar de Roberto da Silveira e Leonel Brizola defenderem a tese do PTB lançar a candidatura de Jango, a pressão da ala nacionalista do partido foi determinante para uma nova aliança com o PSD em favor do marechal Henrique Teixeira Lott, cuja candidatura - lançada oficialmente em dezembro de 1959 - gozava de grande prestígio entre os setores nacionalistas do país (D’ARAÚJO, 1996, p. 130-131).

No entanto, a maior parte do PTB paranaense, que desde 1959 mostrava-se propenso a apoiar Jânio Quadros, optou em desobedecer à decisão da Executiva Nacional e passou a fazer campanha de forma velada em prol da chapa Jan-Jan, inclusive Nelson Maculan, que esperava contar com o apoio recíproco de Jânio Quadros, tentando, assim, repetir a fórmula de sucesso utilizada por Souza Naves em 1958. Entretanto, tal situação acabou gerando uma crise interna no PTB do Paraná, uma vez que havia uma pequena ala nacionalista, capitaneada pelo deputado federal José Teixeira da Silveira e, sobretudo, pelo deputado estadual Waldemar Daros, que constantemente denunciava a "traição" dos petebistas paranaenses ao marechal Lott e a Jango.

Embora Waldemar Daros tenha visitado algumas vezes João Goulart no Rio de Janeiro a fim de deixa-lo a par do que ocorria no Paraná, Jango não se opôs ao movimento Jan-Jan, pois o movimento Ihe era útil eleitoralmente (DELGADO, 1989, p. 230). Assim como ocorreu no Diretório paulista, Goulart permitiu que os petebistas paranaenses prosseguissem com a sua campanha em favor da chapa Jan-Jan - o que evidenciava o desmoronamento da aliança PSD-PTB. Acerca disso, Maria Celina D’Araújo (1996, p. 133134) observa que:

[...] Esta chapa alternativa reflete a estratégia eleitoral adotada. O importante era fazer de Goulart o vice-presidente, e diante do mau desempenho de Lott os petebistas ficaram liberados para outras composições: Jânio-Goulart ou AdhemarGoulart. O que interessava era o apoio ao presidente do partido, e nesse caso a "traição" a Lott era bem-vinda. Não o foi, contudo, quando certos petebistas decidiram apoiar outro candidato a vice, mesmo mantendo o apoio a Lott. Para estes, o caminho foi a expulsão.

Portanto, Jango, de forma velada, liberou os petebistas paranaenses de qualquer compromisso com Lott, desde que se comprometessem em neutralizar a campanha à vice- 
presidência do dissidente trabalhista Fernando Ferrari (que concorria pelo Movimento Trabalhista Renovador - MTR), que estava em ascensão no Paraná.

Durante a campanha eleitoral, Nelson Maculan, embora adotasse uma posição dúbia, evitou participar de comícios ao lado do marechal Lott, assim como muitos petebistas paranaenses procuraram evitar o contato com o candidato pessedista a fim de evitar constrangimentos. Simultaneamente, o deputado estadual Waldemar Daros, que defendia incondicionalmente a candidatura Lott-Jango, tecia duras críticas aos seus colegas de partido, tanto na tribuna da Assembleia Legislativa quanto por meio de violentos manifestos publicados na imprensa. Daros também frequentemente informava a "traição" do seu partido ao próprio marechal Lott, que pressionava Jango para intervir no PTB paranaense.

Contudo, a campanha política de Nelson Maculan, ancorada principalmente na solução dos problemas dos cafeicultores do norte do estado, era acusada de ser demasiadamente elitista e não emplacou em diversas regiões do Paraná, sobretudo em Curitiba, onde o candidato petebista ainda era um ilustre desconhecido. Por outro lado, estava em ascensão a campanha eleitoral de Ney Braga, que prometia resolver o problema do abastecimento de energia elétrica no Paraná.

Com o esvaziamento da candidatura do pessedista Plínio Franco Ferreira da Costa, a eleição polarizou-se em torno de Nelson Maculan e Ney Braga, que disputaram acirradamente o apoio de Jânio Quadros, que optou em não se manifestar a favor de nenhum dos dois candidatos.

Sem o apoio oficial de Jânio Quadros, Ney Braga contou com o apoio da maior parte da UDN, de parte do PR e de setores da Igreja católica. Por sua vez, Maculan foi apoiado pelo ex-governador Bento Munhoz da Rocha Neto, pelos udenistas do norte, por parte do PSP, pela dissidência do PSD e pelo Partido Comunista do Paraná, que chegou a publicar um manifesto ${ }^{31}$ de apoio ao marechal Lott, Jango e Maculan.

Em uma visita a Curitiba, Luís Carlos Prestes confirmou o seu apoio a Lott-Jango ${ }^{32}$ e a Maculan, conclamando os comunistas a votarem nos candidatos trabalhistas (DIÁRIO DA TARDE, 20/09/1960, p. 1). Obviamente, tal fato foi muito explorado pela imprensa paranaense, que "denunciava" os vínculos entre Maculan e os comunistas. Soma-se a isso um boato, que foi amplamente divulgado, de que Maculan no passado teria participado do

31 O referido manifesto foi assinado pelos seguintes líderes do Partido Comunista no Paraná: Agliberto Vieira de Azevedo, Dante Leonelli, Jorge Karam, Júlio Manfredini, Manoel Jacinto Correa e Vieira Netto (O ESTADO DO PARANÁ, 14/08/1960, p. 4). No entanto, esses mesmos líderes comunistas, posteriormente, iriam denunciar que o PTB do Paraná era janista e que estava traindo as candidaturas de Lott e Jango (DIÁRIO DA TARDE, 23/09/1960, p. 1).

32 "Apesar de Lott ser reconhecido como elemento visceralmente anticomunista e de manifestar-se sempre contrariamente à legalização do PCB, [...] paradoxalmente Luís Carlos Prestes fez circular um documento intitulado 'Por que os comunistas apóiam Lott e Jango'” (DELGADO, 1989, p. 229). 
Partido Comunista. Embora Nelson Maculan tenha recusado publicamente o apoio de Prestes e dos comunistas, Léo de Almeida Neves (2002, p. 156) lembra que:

[...] O repúdio de Maculan e do PTB a esse gesto de Prestes repercutiu menos do que a notícia espalhada por todo o Paraná sobre os vínculos do Maculan com o comunismo. Nas missas de domingo, dia das eleições, os padres, na sua maioria, conclamavam os fiéis a derrotar o demônio, encarnado no "Maculan vermelho".

Em suma, além da imprensa, setores da Igreja católica também passaram a explorar os supostos laços entre o candidato trabalhista e os comunistas, favorecendo a candidatura de Ney Braga. De acordo com José Pedro Kunhavalik (2004, p. 276):

O apoio da Igreja a Ney Braga também vem de outras formas. O jornal Voz do Paraná, vinculado à Arquidiocese de Curitiba, faz campanha sistemática contra o comunismo e contra o candidato "comunista" (Nelson Maculan), defendendo a candidatura Ney Braga, embora nem sempre explicitamente.

Desse modo, Ney Braga venceu Nelson Maculan por uma pequena margem de votos $^{33}$. Conforme José Pedro Kunhavalik (2004, p. 278):

Ney Braga vinculou sua campanha e sua imagem a de Jânio Quadros desde o início, criando a dobradinha Ney-Jânio. Nos comícios era dito que quem era Ney era Jânio, e quem era Jânio era Ney. Utilizou os mesmos elementos simbólicos, particularmente o da vassoura, significando que seu governo iria varrer a corrupção no Estado. Assim como Jânio construiu a imagem anti-Adhemar, Ney Braga se fez o anti-Lupion. Este era empresário, amigo de Adhemar de Barros e governador do Estado, acusado, na época, de corrupção. Além disso, Ney Braga fez uso do slogan do "tostão contra o milhão".

Ancorando a sua campanha eleitoral em uma série de fortes denúncias contra Lupion, inclusive prometendo mandá-lo para a cadeia, Ney Braga, de acordo com Marion Magalhães (2001, p. 66), também utilizou diversas técnicas de marketing político, como panfletos, cartazes, programas de rádio e um jingle, amplamente divulgado na época:

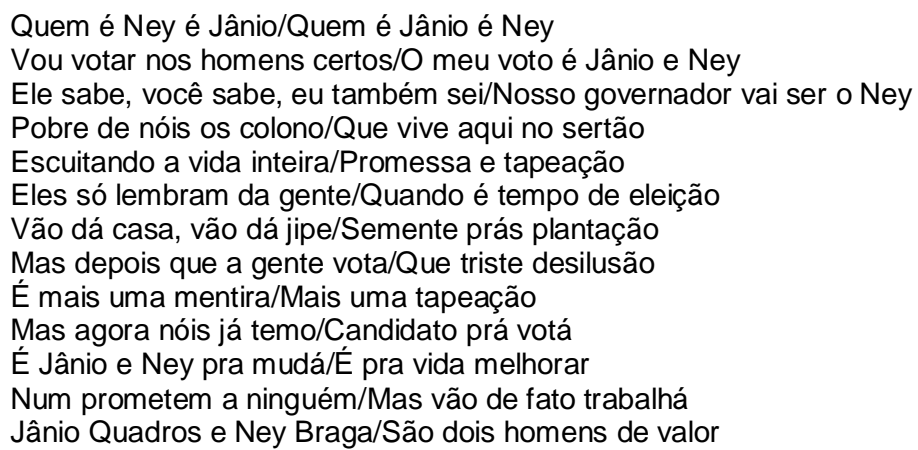

33 Ney Braga obteve 35,3\% dos votos, enquanto Nelson Maculan obteve 30,9\% e Plínio Franco Ferreira da Costa obteve $26,8 \%$. (IPARDES, 1989, p. 11). 


\begin{abstract}
Um vai sê o presidente/E o outro governador
Pra melhorar a vida/Desse povo sofredor

Pra terminar estes versos/Que eu mesmo inventei

Vou pô um fim na conversa/Lembrando que já falei:

Vamos votá nas urnas/Na dobradinha Jânio e Ney.
\end{abstract}

Entretanto, a derrota eleitoral de Maculan frustrou o PTB, que ambicionava conquistar o governo do Paraná pela primeira vez. Nesse sentido, deve-se compreender a opção do Diretório petebista paranaense em apoiar, mesmo de maneira velada, a candidatura de Jânio Quadros como uma estratégia política regional e puramente eleitoral, uma vez que o ex-governador paulista era um nome eleitoralmente mais forte do que o marechal Lott, sobretudo no norte do estado. Em outras palavras, o PTB paranaense pretendia repetir a fórmula de sucesso utilizada por Souza Naves em 1958. Porém, agora o contexto era outro: em primeiro lugar, porque Jânio preferiu não se comprometer oficialmente com ninguém, uma vez que possuía vínculos político-partidários tanto com o PTB quanto o PDC. Em segundo lugar, porque Nelson Maculan, além de não ser um bom orador, não tinha a mesma popularidade de Souza Naves e a sua candidatura não era unanimidade nem mesmo entre os petebistas, uma vez que circulavam notícias de que alguns diretórios do interior estavam apoiando Ney Braga ou o pessedista Plínio Costa.

De fato, Nelson Maculan enfrentava resistências de algumas frações dentro do PTB, sobretudo pelo seu passado udenista. Comentava-se nos bastidores que Maculan havia caído de pára-quedas no partido e na vaga ao Senado deixada pela morte de Souza Naves. De qualquer modo, a derrota eleitoral em 1960 foi um duro golpe para os petebistas e Nelson Maculan foi muito criticado pelos seus correligionários, sobretudo pela maneira dúbia em que conduziu a campanha (DIÁRIO DA TARDE, 17/11/1960, p. 1). Assim, os trabalhistas voltaram a lamentar a morte do seu antigo líder Souza Naves, sobretudo porque acreditavam que ele teria vencido o pleito de 1960 e o PTB teria conquistado o governo do estado.

No que concerne às eleições presidenciais, Jânio Quadros elegeu-se presidente da República, obtendo $48 \%$ dos votos contra $28 \%$ do marechal Henrique Lott e $23 \%$ de Adhemar de Barros. Para a vice-presidência, João Goulart venceu a disputa contra Milton Campos (UDN) e Fernando Ferrari (MTR) (FAUSTO, 2006, p. 241).

Apesar da sua firme posição nacionalista, o marechal Lott mostrou-se um mau candidato, com fraco carisma eleitoral, pouca habilidade política e um rigor militar, ao contrário de Jânio Quadros, que teve maior penetração junto às camadas mais populares (DELGADO, 1989, p. 230). Ademais, Jânio era melhor orador e valeu-se de expedientes teatrais, utilizando uma vassoura e um conhecido jingle ("Varre, varre, vassourinha") como 
principais elementos simbólicos da sua campanha, centrada nos ataques à "corrupção do governo anterior, à inflação e à alta do custo de vida, ao desperdício com as obras faraônicas de Brasília e às irresponsabilidades do 'presidente voador"'. Além de contar com o decisivo apoio de Carlos Lacerda e da UDN, Jânio também atraiu os votos dos descontentes, dos sem-partido, dos militares, das classes médias e da burguesia (por meio das promessas de "limpeza" na administração e de estabilização da economia) e ainda foi capaz de "entusiasmar as massas operárias com tiradas esquerdistas" (BENEVIDES, 1982, p. 22-26).

No Paraná, Jânio Quadros venceu com uma grande margem de votos, enquanto o marechal Lott obteve um baixo desempenho, conforme demonstra a tabela abaixo:

Tabela 1 - Resultado das eleições presidenciais de 1960 no Paraná

\begin{tabular}{|c|c|c|c|}
\hline Candidatos & Partido/coligação & Número de votos & Percentual (\%) \\
\hline Jânio Quadros & PDC-UDN & 367.422 & $51,2 \%$ \\
\hline Adhemar de Barros & PSP & 161.802 & $22,6 \%$ \\
\hline Mal. Henrique Teixeira Lott & PSD-PTB & 121.462 & $16,9 \%$ \\
\hline Brancos & & 45.397 & $6,3 \%$ \\
\hline Nulos & & 21.297 & $3 \%$ \\
\hline Total & & 717.380 & $100 \%$ \\
\hline
\end{tabular}

Fonte: IPARDES (1989, p. 9).

Um fator que contribuiu para o fraco desempenho eleitoral do marechal Henrique Lott no Paraná deve-se ao fato da maior fração do PTB paranaense ter apoiado Jânio Quadros, que também contou com o apoio do eleitorado neyista e udenista. Soma-se a isso também a popularidade de Adhemar de Barros no norte do estado. Por outro lado, a estratégia eleitoral de João Goulart em liberar o Diretório petebista para fazer campanha em prol da chapa JanJan e, assim, combater Fernando Ferrari surtiu efeito no Paraná, uma vez que Jango obteve $30,9 \%$ dos votos, contra $25,9 \%$ do udenista Milton Campos e $18,9 \%$ de Fernando Ferrari (IPARDES, 1989, p. 10).

\section{A Renúncia de Jânio Quadros e a Campanha da Legalidade no Paraná}

Jânio Quadros, o primeiro presidente a ser empossado em Brasília, governou o país por apenas sete meses, em um período marcado pela grave crise econômica e pela intensa mobilização dos movimentos sociais (urbanos e rurais). Seu curto governo ficaria marcado 
pelo moralismo extremado ${ }^{34}$ e por uma série de ambiguidades e contradições, que desagradaram tanto os setores conservadores quanto as esquerdas.

Por um lado, Jânio procurou aplicar uma política econômica liberal visando a abrir o mercado brasileiro aos investimentos estrangeiros. Também renegociou a dívida externa do país com o Fundo Monetário Internacional (FMI) e buscou empréstimos junto aos norteamericanos. Em virtude da inflação galopante, adotou uma política econômica ortodoxa, envolvendo uma forte desvalorização cambial, contenção de gastos públicos, redução de subsídios, entre outras coisas ${ }^{35}$ (Cf. CHAIA, 1991, p. 209-212), o que desagradou os grupos nacionalistas e reformistas.

Por outro lado, uma das medidas mais surpreendentes de Jânio foi a adoção da Política Externa Independente, que resultou no reatamento das relações diplomáticas do Brasil com os países do bloco comunista e, posteriormente, na condecoração de Ernesto "Che" Guevara em território brasileiro. Porém, tais medidas atraíram a oposição dos consenadores, sobretudo da UDN. Dessa maneira, conforme Maria Victoria Benevides (1982, p. 32-33), todos pertenciam ao governo, em um caleidoscópio que iluminava ora o moralismo bacharelesco da UDN, ora o conservadorismo burocrático e o industrialismo do PSD, ou o trabalhismo do PTB e a crescente participação dos sindicatos.

Inicialmente, o PTB apoiou o governo de Jânio Quadros, participando com três dos dez ministérios civis (Agricultura, Justiça e Trabalho) e possuindo fortes afinidades no que tange à Política Externa Independente - o que contribuiu para o rompimento entre o PTB e o PSD (D'ARAÚJO, 1996, p. 135). Entretanto, não tardou para o PTB se desentender com Jânio. Segundo Maria Celina D’Araújo (1996, p. 135):

[...] Isso ocorreu principalmente devido aos métodos usados pelo governo para apurar irregularidades político-administrativas anteriores, refletindo, segundo o líder do PTB, Almino Affonso, uma atitude extremamente hostil em relação à classe política. Mais de 30 comissões de sindicância foram criadas na época, a maioria presidida por militares. Duas delas, por exemplo, envolviam diretamente a ação de João Goulart junto ao IAPB e ao Saps. Em função disso, em maio de 1961, o PTB declarava rompidas suas relações com o governo, apesar de simpatizar com os rumos da diplomacia brasileira.

Com uma fúria inquisitorial, a "cruzada moralizadora" de Jânio Quadros atingiu principalmente o PSD e o PTB, que, unidos na oposição, criticaram o arbítrio e a perseguição do presidente (Cf. BENEVIDES, 1989, p. 68-69; CHAIA, 1991, p. 194-197). E mais, o estilo bonapartista e centralizador de Jânio o levaram a uma série de

34 Por exemplo, Jânio Quadros proibiu o biquíni, o lança-perfume e a briga de galos. Mais detalhes ver CHAIA (1991, p. 198-199).

35 Mais detalhes acerca da política econômica do governo Jânio Quadros ver Loureiro (2012). 
desentendimentos com o Congresso, onde todos "condenavam o uso abusivo de vetos do presidente" (BENEVIDES, 1989, p. 68-69).

Em suma, por várias razões, Jânio conseguiu descontentar a maior parte dos setores políticos, pois suas medidas dúbias ora desagradavam os conservadores, ora os reformistas. Sofrendo a oposição do PTB e do PSD e não gozando da confiança dos setores militares, Jânio passou a enfrentar críticas da UDN, perdendo a sua base de apoio político.

Assim, Jânio também foi vítima da "metralhadora giratória" de Carlos Lacerda. No dia 24 de agosto de 1961, o agora governador da Guanabara criticou duramente, na televisão, o presidente, acusando-o de possuir intenções golpistas. No dia seguinte, surpreendentemente, Jânio renunciou (Cf. LABAKI, 1986). Embora os motivos e objetivos da renúncia não tenham sido totalmente esclarecidos, sem dúvida tratou-se de uma manobra política, no mínimo, equivocada:

\begin{abstract}
Aparentemente, Jânio esperava voltar "nos braços do povo". [...] Confiava no temor dos militares e da direita em geral com a "ameaça" da posse de João Goulart. Confiava também no temor da esquerda com a possível instalação de uma junta militar no governo se este fosse declarado acéfalo, pois o vice-presidente encontrava-se em missão oficial na China. Enfim, Jânio esperava contar com a repercussão na opinião pública (afinal, eram seis milhões de votos), entre os militares, na direita e na esquerda, e talvez imaginasse o ressurgimento de um novo "queremismo" (BENEVIDES, 1982, p. 76-77).
\end{abstract}

Como a maioria do Congresso prontamente aceitou a renúncia, a partir de então a questão da investidura do vice-presidente João Goulart provocou uma grave crise políticomilitar. Com Jango em missão diplomática na China comunista, o presidente em exercício Ranieri Mazzilli - presidente da Câmara dos Deputados - enviou uma mensagem ao Congresso Nacional "comunicando que os três ministros militares (Odílio Denys, Grum Moss e Sylvio Heck) manifestaram-Ihe a inconveniência do regresso de Goulart ao Brasil". Os ministros militares, que viam em João Goulart o herdeiro político de Vargas, o fantasma da república sindicalista e a ameaça comunista, vetaram a sua posse e defendiam abertamente, juntamente com a ala golpista da UDN, a quebra da legalidade constitucional (FERREIRA, 2003, p. 327).

Ao tomar conhecimento das conspirações golpistas, o governador do Rio Grande do Sul, cunhado e principal aliado político de Jango, Leonel Brizola deu início à Campanha da Legalidade, na qual defendia o cumprimento da legalidade constitucional e a consequente posse de Goulart. Para tais propósitos, Brizola, apoiado na Brigada Militar, mobilizou a população de Porto Alegre e desafiou as Forças Armadas, que, inclusive, ameaçaram bombardear o Palácio Piratini. 
Entretanto, nem todos os militares eram favoráveis ao golpe. Além do marechal Henrique Lott ${ }^{36}$, o general Machado Lopes, comandante do III Exército, que tinha ordens para invadir o Palácio do governo sul-rio-grandense, rompeu com o ministro da Guerra Odílio Denys e aliou-se a Brizola na defesa da legalidade.

No Paraná, a ameaça da guerra civil era acompanhada com apreensão nos círculos políticos, que, em sua maioria, apoiava a posse de Goulart. Segundo o depoimento de Léo de Almeida Neves (2002, p. 161), naquela época deputado estadual pelo PTB:

[...] O prefeito de Curitiba, general Iberê de Mattos [PTB], abriu voluntariado para quem quisesse participar da luta armada, caso ela viesse a ocorrer (milhares de pessoas se alistaram). Esse trabalho foi coordenado pelo jornalista Jorge Mathias Júnior [PTB], secretário político do prefeito, a quem atribuiu plenos poderes para o cumprimento da missão.

$\mathrm{Na}$ Assembleia Legislativa paranaense, que ficou em sessão permanente de 25 de agosto a 4 de setembro, a legalidade era defendida enfaticamente, sobretudo pela bancada do PTB paranaense. O PSD do Paraná também esteve ao lado da legalidade, apesar do senador pessedista Alô Guimarães ter votado contra a posse de Jango. Por sua vez, a UDN do Paraná inicialmente adotou uma postura dúbia (GAZETA DO POVO, 31/08/1961, p. 3), não deixando claro se apoiava ou não a posse de Goulart, embora apenas o deputado federal Othon Mader declarava-se contrário à posse de Jango.

No dia 28 de agosto, o deputado estadual udenista Aníbal Khury leu na tribuna um manifesto do "Movimento Popular Pró-Jânio no Paraná", defendendo a recondução de Jânio à presidência. Porém, os seus argumentos foram rechaçados por Amaury de Oliveira e Silva ${ }^{37}$, líder da bancada petebista, e, no mesmo dia, a Assembleia manifestou-se favorável ao cumprimento da Constituição e da posse de João Goulart (DIÁRIO DO PARANÁ, 29/08/1961, p. 3).

Por sua vez, o governador Ney Braga também adotou uma posição dúbia, não deixando claro se apoiava os ministros militares, que vetavam a posse de Jango, ou se estava ao lado da legalidade. Embora não se manifestasse oficialmente, Ney Braga era contrário à posse de Jango e também defendia o retorno de Jânio Quadros, conforme mensagem divulgada no dia 28 de agosto:

36 O marechal Henrique Teixeira Lott, reformado, mas com grande prestígio político, distribuiu, na noite do dia 25, um manifesto à Nação apoiando a posse de Goulart e convocando o povo a preservar a ordem legal e a Constituição. Acabou preso por ordens do ministro da Guerra, Odílio Denys. In: FERREIRA (2003, p. 327).

37 Léo de Almeida Neves (2002, p. 169) destaca que Amaury Silva foi o petebista que mais se destacou na Campanha da Legalidade no Paraná. 
Julgo que a melhor situação é a volta de Jânio, com a união nacional dos homens de bem, livrar o Brasil das peias que o levaram à renúncia. [...] Se Jânio não pôde, ninguém governará o Brasil com as mesmas amarras que ele denunciou à Nação (TRIBUNA DO PARANÁ, 29/08/1961, p. 7).

A posição dúbia de Ney Braga foi criticada não somente pela bancada petebista na Assembleia (DIÁRIO DA TARDE, 29/08/1961, p. 5), mas também por estudantes, sindicalistas, nacionalistas e pela imprensa (DIÁRIO DA TARDE, 30/08/1961, p. 3), que estavam ao lado de Brizola na Campanha da Legalidade, que ganhou forte apoio popular no Paraná. Inclusive, foram organizados diversos comícios e manifestações por estudantes, sindicalistas, jornalistas e lideranças políticas - sobretudo do PTB - em favor da posse de Goulart (DIÁRIO DA TARDE, 29/08/1961, p. 1). Além disso, também foi organizada pelo prefeito de Curitiba, general Iberê de Mattos, a "Cadeia da Legalidade", na qual, por meio da Rádio Guairacá, o general lberê e alguns deputados estaduais pronunciavam veementes discursos conclamando o povo a defender o regime democrático e a posse de Goulart (DIÁRIO DA TARDE, 01/09/1961, p. 4).

Ademais, a V Região Militar (Paraná e Santa Catarina), sediada em Curitiba e comandada pelo general Benjamin Rodrigues Galhardo, manteve-se fiel ao III Exército na defesa da Legalidade, chegando a deslocar tropas para a fronteira com São Paulo visando a impedir o deslocamento das tropas golpistas ao Rio Grande do Sul (DIÁRIO DO PARANÁ, 31/08/1961, p. 1; DIÁRIO DA TARDE, 31/08/1961, p. 1).

Se, por um lado, apenas o governador goiano Mauro Borges (PSD) acompanhou Brizola na resistência frontal aos ministros militares, por outro eclodiram diversas mobilizações populares em defesa da legalidade em todo o país. Além dos sindicatos, a ordem constitucional também era exigida por outros segmentos sociais, como setores da Igreja católica, a maioria dos partidos políticos, estudantes, intelectuais, associações comerciais e profissionais, frações das Forças Armadas e da imprensa, dentre diversos outros grupos sociais e instituições políticas (FERREIRA, 2003, p. 333-334). Portanto, com o avanço das forças legalistas, qualquer tentativa de golpe não encontraria o menor respaldo político e social.

Como o Congresso não aceitou votar pelo impedimento de Goulart, os ministros militares, isolados politicamente, aceitaram negociar uma solução intermediária, que lhes garantisse uma "saída honrosa" do episódio. Assim, a solução encontrada pelo Congresso foi a adoção da emenda parlamentarista, cujo objetivo principal era reduzir os poderes do presidente.

No dia $1^{\circ}$ de setembro de 1961, em Montevidéu, ocorreram as negociações entre Tancredo Neves (PSD) e João Goulart, que, mesmo contrariado, aceitou assumir a 
presidência da República sob a tutela parlamentarista38. Na noite do mesmo dia, Jango chegou a Porto Alegre e, na madrugada do dia 2 de setembro, o Congresso aprovou a emenda parlamentarista por 233 votos contra 55.

Por sua vez, Leonel Brizola negava-se a aceitar o acordo parlamentarista, posição compartilhada pela maioria dos deputados estaduais do PTB paranaense. Amaury Silva apelou para que o senador e presidente do PTB paranaense Nelson Maculan votasse contra a emenda, porém Maculan acabou votando favoravelmente e foi acusado de "traidor" pelo deputado estadual João Cernicchiaro (DIÁRIO DO PARANÁ, 05/09/1961, p. 3). Aliás, na bancada paranaense no Congresso houve apenas dois votos contrários à emenda parlamentarista: dos petebistas Antônio Baby e José Teixeira da Silveira39.

De acordo com Jorge Ferreira (2003, 2011), João Goulart aceitou a solução parlamentarista para evitar a guerra civil. Assim, chegou a Brasília no dia 5 de setembro, assumindo a presidência da República no dia 7 de setembro. Jânio Quadros, por sua vez, após a renúncia à presidência e o período na Europa, retornou ao Brasil para concorrer ao governo de São Paulo nas eleições de 1962. Porém, desgastado politicamente com a renúncia, Jânio conheceu a sua primeira derrota eleitoral com a vitória do seu principal adversário politico, Adhemar de Barros, ao governo paulista40. Portanto, a derrota eleitoral de 1962 evidenciou o enfraquecimento politico de Jânio Quadros. Embora tenha sido hostil ao governo de João Goulart e simpático ao golpe civil-militar de 1964, Jânio teve os seus direitos políticos cassados com o Ato Institucional no 1 (Al-1), de 9 de abril de 1964.

Em 1968, durante o governo do general Arthur da Costa e Silva, Jânio foi punido com a prisão por quatro meses em Corumbá (no então estado de Mato Grosso, hoje Mato Grosso do Sul) por desrespeitar a proibição de fazer pronunciamentos políticos (CHAIA, 1991, p. 251). Jânio somente voltaria à cena politica a partir da anistia politica de 1979 , porém sem abandonar o seu estilo. Assim, em 1982, concorreu ao governo de São Paulo pelo PTB, porém foi novamente derrotado, ficando atrás de Franco Montoro (do Partido do Movimento Democrático Brasileiro - PMDB) e Reinaldo de Barros (do Partido Democrático Social - PDS). No entanto, em 1985, Jânio foi eleito prefeito de São Paulo, derrotando o então senador Fernando Henrique Cardoso (PMDB). Após o fim do seu mandato na capital paulista, Jânio, sofrendo com problemas de saúde, optou em não concorrer às eleições

38 Mais detalhes acerca das negociações entre Jango e Tancredo Neves ver Ferreira (2011, p. 250-258).

39 Portanto, além do senador Nelson Maculan, os deputados federais petebistas Petrônio Fernal, Miguel Buffara, Jorge de Lima e Kalil Maia Neto votaram favoravelmente à emenda parlamentarista. Entretanto, Nelson Maculan justificou-se, argumentando que seguiu a orientação da bancada nacional petebista e que o próprio João Goulart havia concordado com a solução conciliatória parlamentarista (DIÁRIO DA TARDE, 05/09/1961, p. 3).

40 Mais detalhes ver CHAIA (1991, p. 243-250). 
presidenciais de 1989 - a primeira eleição direta à presidência da República após 29 anos. (Cf. CHAIA, 1991, p. 252-303). Com a saúde debilidade, Jânio Quadros faleceu em 16 de fevereiro de 1992.

\section{Considerações Finais}

Oriundo de uma família paranaense, Jânio Quadros viveu parte da sua infância e adolescência no Paraná, mudando-se para São Paulo na década de 1930, onde se bacharelou em Direito e iniciou a sua meteórica carreira política em 1947. Durante o auge da sua carreira política (no final da década de 1950 e início da década de 1960), Jânio também gozou de enorme prestígio político no Paraná, o que contribuiu para que o PTB paranaense o lançasse como candidato a deputado federal em 1958 pelo estado. Tal fato, pouco abordado pela historiografia, foi decisivo para a vitória eleitoral do PTB no Paraná nas eleições legislativas de 1958, levando o partido a tentar a repetir a fórmula de sucesso nas eleições ao governo paranaense em 1960 e a defender a chapa Jan-Jan (Jânio-Jango) nas eleições presidenciais de 1960. Conforme abordamos no presente artigo, Jânio Quadros, além de ter obtido uma enorme votação no Paraná em 1960, também contribuiu para a vitória de Ney Braga - que vinculou a sua campanha e a sua imagem a de Jânio - ao governo estadual.

No entanto, a renúncia de Jânio à presidência, em agosto de 1961, catalisou uma grave crise política no país, que também repercutiu intensamente no Paraná, e contribuiu para o seu enfraquecimento político. Derrotado nas eleições à sucessão paulista de 1962 , cassado pelo Al-1, Jânio somente retornou ao cenário político em 1979, mas agora a sua força e influência política eram limitadas e restritas ao estado de São Paulo.

\section{Referências}

BATISTELLA, Alessandro. O Partido Trabalhista Brasileiro no Paraná (1945-1965). Curitiba: UFPR, 2016.

BENEVIDES, Maria Victoria de Mesquita. O governo Jânio Quadros. 2. ed. São Paulo: Brasiliense, 1982.

BENEVIDES, Maria Victoria de Mesquita. O PTB e o trabalhismo: partido e sindicato em São Paulo (1945-1964). São Paulo: Brasiliense, 1989.

CHAIA, Vera Lúcia M. A liderança politica de Jânio Quadros (1947-1990). Ibitinga: Humanidades, 1991. 
D’ARAÚJO, Maria Celina. Sindicatos, carisma \& poder: o PTB de 1945-1965. Rio de Janeiro: FGV, 1996.

DELGADO, Lucília de Almeida Neves. PTB: do getulismo ao reformismo (1945-1964). São Paulo: Marco Zero, 1989.

DIÁRIO DA TARDE. Curitiba, 14 ago. 1958; 14 dez. 1959; 23 set. 1960; 20 set. 1960; 17 nov. 1960; 29 ago. 1961; 30 ago. 1961; 31 ago. 1961; $1^{\circ}$ set. 1961; 5 set. 1961.

DIÁRIO DO PARANÁ. Curitiba, 21 mar. 1961; 12 abr. 1961; 29 ago. 1961; 31 ago. 1961; 5 set. 1961.

FAUSTO, Boris. História concisa do Brasil. 2. ed. São Paulo: EDUSP, 2006.

FERREIRA, Jorge. Crise da República: 1954, 1955 e 1961. In: FERREIRA, Jorge; DELGADO, Lucilia de Almeida Neves (org.). O Brasil republicano: o tempo da experiência democrática (1945-1964). Rio de Janeiro: Civilização Brasileira, 2003. v. 3, p. 301-342.

FERREIRA, Jorge. João Goulart: uma biografia. 4. ed. Rio de Janeiro: Civilização Brasileira, 2011.

GAZETA DO POVO. Curitiba, 17 dez. 1957; 30 jul. 1958; 22 ago. 1958; 23 ago. 1958; 28 ago. 1958; 31 ago. 1958; 31 mar. 1959; 4 jun. 1959; 19 maio 1959; 18 nov. 1959; 15 dez. 1959; 31 ago. 1961.

IPARDES - INSTITUTO PARANAENSE DE DESENVOLVIMENTO ECONÔMICO E SOCIAL. Resultados eleitorais: Paraná (1945-1982). Curitiba: IPARDES, 1989.

KUNHAVALIK, José Pedro. Ney Braga: trajetória política e bases do poder. In: OLIVEIRA, Ricardo Costa (org.). A construção do Paraná moderno: políticos e política no governo do Paraná de 1930 a 1980. Curitiba: SETI, 2004. p. 231-411.

LABAKI, Amir. 1961: a crise da renúncia e a solução parlamentarista. São Paulo: Brasiliense, 1986.

LOUREIRO, Felipe Pereira. Empresários, trabalhadores e grupos de interesse: a Política Econômica nos governos Jânio Quadros e João Goulart, 1961-1964. 2012. Tese (Doutorado em História Econômica) - Universidade de São Paulo, São Paulo, 2012.

MAGALHÃES, Marion Brepohl. Paraná: política e governo. Curitiba: SEED, 2001. (Coleção História do Paraná).

NEVES, Léo de Almeida. Vivência de fatos históricos. São Paulo: Paz e Terra, 2002.

O DIA. Curitiba, 15 ago. 1958; 23 ago. 1958; 5 fev. 1960.

O ESTADO DO PARANÁ. Curitiba, 14 ago. 1960.

QUELER, Jefferson José. Entre o mito e a propaganda política: Jânio Quadro e a sua imagem pública (1959-1961). 2008. Tese (Doutorado em História) - Universidade Estadual de Campinas, Campinas, 2008. 


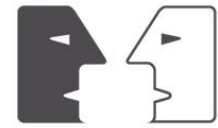

ANTITESES

REHBEIN, Mauro Pioli. Curitiba: 50 anos de eleições municipais. As forças políticas que na democracia e no governo militar disputam o poder. 2008. Dissertação (Mestrado em Sociologia) - Universidade Federal do Paraná, Curitiba, 2008.

TRIBUNA DO PARANÁ. Curitiba, 29 ago. 1961.

VALENTE, Nelson. A vida de Jânio Quadros. São Paulo: Nacional, 1993.

Recebido em 07/02/2018

Aprovado em 12/11/2018 